Abstract P0-0663 Table 1 Incidence of congenital anomalies based on race, birth weight, and antenatal detection

\begin{tabular}{|c|c|c|c|c|c|c|c|}
\hline \multirow[b]{2}{*}{ Anomalies } & \multicolumn{3}{|l|}{ Ethnicity } & \multicolumn{2}{|c|}{ Low birth weight (LBW) } & \multicolumn{2}{|c|}{ Antenatal detection } \\
\hline & Hispanics & African A. & Asians and others & $<2.5 \mathrm{~kg}$ & $>2.5 \mathrm{~kg}$ & Prenatal & Postnatal \\
\hline Major & 279 & 104 & 15 & 96 & 302 & 145 & 253 \\
\hline Minor & 1444 & 457 & 49 & 148 & 1802 & 962 & 988 \\
\hline
\end{tabular}

Introduction Transfer of behavioural skills learnt in the simulation room to the delivery room setting has not been well addressed.

Methodology We queried the physicians and nurses who participated in resuscitation in an actual delivery room setting. Their training included simulation based training for previous 4 years with emphasis on behavioural skills. Open ended questions included: (1) What went well?, (2) What did not go well?, (3) What would you do differently?, (4) Other comments.

Results 32 events attended by teams of nurses and physicians were the focus of analysis. There was overlapping of physicians and nurses attending different events. 74 nurses and 35 physicians completed questionnaires that formed the database. Teamwork and communication ( 2 hallmarks of behavioural skills) were analysed. $40 / 74(54.05 \%)$ of nurses and 13/35 (37.14\%) of physicians responded that teamwork was good. 11/74 (14.86\%) of nurses and 12/35 (34.28\%) physicians responded that communication was good. None of the nurses commented negatively about the teamwork bur 2/35 (5.71\%) physicians mentioned that teamwork did not go well. 10/74 (13.51\%) of nurses and 6/35 (17.24\%) of physicians mentioned that communication was not good. Thus, $68.91 \%$ of nurse responses and $71.42 \%$ of physician responses were favourable for teamwork and communication. Calling for help and delegating responsibility were also noted on the responses.

Discussion Based on our open ended questionnaire, we conclude that physicians and nurses consider teamwork and communication to be important and these skills are being utilised in the delivery room setting. These results encourage us to continue our study.

\section{P0-0662 UMBILICAL CORD BLOOD GASES ANALYSIS IN PREGNANCIES COMPLICATED BY NUCHAL CORD}

${ }^{1} \mathrm{R}$ Vasa, ${ }^{2} \mathrm{~S}$ Patel, ${ }^{3} \mathrm{R}$ Dimitrov. ${ }^{1}$ Pediatrics, Mercy Hospital and Medical Center and University of Chicago, Chicago, USA; ${ }^{2}$ Pediatrics, Mercy Hospital and Medical Center, Chicago, USA; ${ }^{3}$ Biostatistics, Mercy Hospital and Medical Center, Chicago, USA

\subsection{6/archdischild-2014-307384.1303}

Introduction Cardio-pulmonary compromise in fetus and newborn secondary to loose or tight nuchal cord at or prior to delivery is an important area for research. Our aim in this study is to evaluate umbilical arterial (UA) and venous (UV) $\mathrm{pH}, \mathrm{pO}_{2}$, $\mathrm{pCO}_{2}$, base deficit and the umbilical veno-arterial difference $(\mathrm{Uv}-\mathrm{a})$ in these parameters in newborns born following nuchal cord.

Methodology UA and UV $\mathrm{pH}, \mathrm{pO}_{2}, \mathrm{pCO}_{2}$, and base deficit of 47 newborns born following tight nuchal cord, 44 newborns born following single loose nuchal cord and 44 newborns born without nuchal cord were compared across.

Results Mean UA pH (7.25 vs. 7.28) was lower in the nuchal cord group and mean UA $\mathrm{pCO}_{2}$ (58.11 vs. 54.38$)$ was higher in the nuchal cord group; however the difference was not statistically significant. No difference was found in $\mathrm{pO}_{2}$ or base deficit across groups. However, nuchal cord to control group comparisons of $\mathrm{U} \mathrm{v}-\mathrm{a} \mathrm{pH}$ and $\mathrm{U} \mathrm{v}-\mathrm{a} \mathrm{pCO}_{2}$ change were both significant $(\mathrm{p}<0.05)$. No $\mathrm{U} v-\mathrm{a} \mathrm{pH}$ and $\mathrm{pCO}_{2}$ differences between control and tight nuchal cord were observed. $\mathrm{U} v-\mathrm{a} \mathrm{pO}_{2}$ difference and $\mathrm{U} \mathrm{v}$-a base deficit difference was also non-significant across groups.

Discussion UA acidosis was observed in group with nuchal cord, as seen by lower mean UA $\mathrm{pH}$ and elevated UA $\mathrm{pCO}_{2}$ (statistical non-significance could be due to low power) and $\mathrm{U}$ v-a difference in $\mathrm{pH}$ and $\mathrm{pCO}_{2}$ (statistically significant). Large prospective studies would be needed to clearly understand the patho-physiology of acidosis in newborns born following nuchal cord.

\section{PO-0663 REVIEW OF BIRTH DEFECTS IN A COMMUNITY HOSPITAL OVER A 10-YEAR PERIOD}

M Vaz, E Erickson, B Rajegowda. Division of Neonatology/Department of Pediatrics, Lincoln Medical and Mental Health Center Affiliate of Weil Medical College/Corn, New York, USA

\subsection{6/archdischild-2014-307384.1304}

Background Birth defects are responsible for majority of morbidity in neonates and are detected antenatally or postnatally.

Aims Our aim is to review types of birth defects that have occurred over a 10-year period in an urban community hospital. Methods Data was analysed retrospectively by reviewing documentation through EMR from January 1, 2003 through December 31, 2012.

Results We analysed the incidence of congenital anomalies based on race, birth weight, and antenatal detection as shown in Table 1 , taking into account the system-based occurrence for any clustering of defects. During the study period, there were 24,203 live births. 2156 infants were identified with congenital anomalies, incidence rate of $8.90 \%$; including multiple anomalies. There were a total of 2348 anomalies, including single and multiple unrelated anomalies. $16.9 \%$ were classified as major and $83.04 \%$ as minor.

Conclusion Chromosomal and major structural anomalies were detected using prenatal testing, like amniocentesis and imaging studies. Despite preventive measures, counselling and termination of pregnancy where applicable, birth defects continue to occur. The recent Federal Policy on monitoring of infants by Pulse Oximetry prior discharge helps to detect ductal dependent cardiac defects and identify those missed by clinical examination, necessitating it as an additional tool.

\section{P0-0664 SUPERGLUE, A SIMPLE AND EFFECTIVE METHOD FOR SEALING AN UNTIGHT CATHETER FOR PERITONEAL DIALYSIS}

M Wald, A Schneider, C Weisser, J Brandner. Department for Pediatrics Division for Neonatology, Salzburger Landeskliniken/Paracelsus Medical University, Salzburg, Austria

10.1136/archdischild-2014-307384.1305 